\title{
FREQUÊNCIA DE IRRIGAÇÃO UTILIZANDO POLÍMERO HIDROABSORVENTE NA PRODUÇÃO DE MUDAS DE MARACUJAZEIRO-AMARELO ${ }^{1}$
}

\author{
RAONI PEREIRA DE CARVALHO², MARIA DO CÉU MONTEIRO CRUZ, \\ LARISSA MADUREIRA MARTINS ${ }^{4}$
}

RESUMO - A produção de mudas de espécies frutíferas com qualidade é realizada em ambiente protegido que, em função das variações da temperatura do ar, necessita de irrigação frequente para manter a umidade no substrato. Desta forma, o trabalho foi realizado com o objetivo de avaliar diferentes frequências de irrigação com a incorporação do polímero hidroabsorvente na produção de mudas de maracujazeiro-amarelo em dois tipos de substrato. As mudas foram produzidas em sacos de polietileno de $650 \mathrm{~mL}$ em casa de vegetação. Foi utilizado o esquema fatorial $2 \times 2 \times 3$, distribuído no delineamento inteiramente casualizado, com quatro repetições e cinco plantas por parcela, sendo uma por recipiente. Os fatores estudados foram duas doses do polímero Hidroplan-EB ${ }^{\mathbb{\circledR}} / \mathrm{HyB}-\mathrm{M}\left(0\right.$ e $\left.3 \mathrm{~g} \mathrm{~L}^{-1}\right)$; dois substratos (solo + esterco na proporção 3:1 (v/v) e Bioplant ${ }^{\mathbb{R}}$ ); e três intervalos de reposição de água (irrigação diária, irrigação em dias alternados e irrigação a cada dois dias). Para analisar o efeito comparativo da incorporação do polímero aos substratos, a avaliação foi realizada quando as mudas emitiram a primeira gavinha, estágio ideal para o plantio no campo. A incorporação do polímero aos substratos proporcionou tamanho das mudas, que foi evidenciado a partir da maior produção de massa seca. Além disso, essas mudas, mesmo com menor frequência de irrigação, apresentaram tamanho semelhante às mudas que receberam irrigação diária e área foliar com maior capacidade de produção de massa seca. Assim, com a incorporação do polímero hidroabsorvente, a irrigação das mudas de maracujazeiro pode ser realizada com menor frequência, com intervalo de um dia em ambos os substratos. A formação das mudas de maracujazeiro-amarelo foi antecipada nos substratos que tiveram incorporação do polímero, alcançando tamanho adequado para o plantio no campo antes daquelas produzidas sem o polímero. Termos para indexação: Passiflora edulis, hidrogel, condicionador de solo, retenção de água.

\section{IRRIGATION FREQUENCY USING HYDRO-ABSORBENT POLYMER IN SEEDLING PRODUCTION OF YELLOW PASSION FRUIT}

\begin{abstract}
The seedlings production of quality fruit species is carried in a protected environment, and frequent irrigation is needed due to air temperature variations and to keep the substrate moist. Thus, this study was carried out to evaluate different irrigation frequencies and the incorporation of hydro-absorbent polymer in the production of yellow passion fruit seedlings in two substrate types. The seedlings were produced in polyethylene bags of $650 \mathrm{~mL}$ in a greenhouse. It was used a factorial scheme $2 \times 2 \times 3$, distributed in a completely randomized design with four replications and five plants per plot, and one per container. The factors studied were two doses of the polymer Hidroplan-EB ${ }^{\circledR} / \mathrm{HyB}-\mathrm{M}$ : 0 and $3 \mathrm{~g} \mathrm{~L}^{-1}$, two substrates: soil

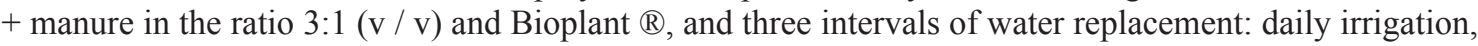
irrigation in alternate days and irrigation every two days. To analyze the comparative effect of polymer incorporation to substrates, the evaluation was performed when the seedlings issued the first vine, which is the ideal stage for field planting. The polymer incorporation in the substrates provided higher seedling size, which was evidenced by the higher dry matter production. Furthermore, these seedlings even with lower irrigation frequency showed similar size to the seedlings that received daily irrigation and leaf area with higher capacity of dry mass production. Thus, irrigation of yellow passion fruit seedlings can be carried with less frequency, with an interval of one day, with the hydro absorbent polymer incorporation in both substrates. The formation of yellow passion fruit seedlings was anticipated in the substrates that had polymer incorporation, achieving adequate size for field planting before those produced without the polymer.
\end{abstract}

Index terms: Passiflora edulis, hydrogel, soil conditioner, water retention.

\footnotetext{
1(Trabalho 146-12). Recebido em: 15-05-2012. Aceito para publicação em: 11-06-2013.

${ }^{2}$ Eng. Agr., Mestrando do programa de Pós-Graduação em Produção vegetal, UFVJM. Rodovia MGT 367- Km 583, nº 5.000, Campus JK, Diamantina, MG, CEP 39100-000. Bolsista da CAPES. Email: raonipc@gmail.com

${ }^{3}$ Pós-D.Sc. em Fitotecnia, Professora do Departamento de Agronomia, UFVJM, Rodovia MGT 367- Km 583, nº 5.000, Campus JK, Diamantina,MG, CEP 39100-000. Email: mariceu@ufvjm.edu.br

${ }^{4}$ Eng. Ag., Mestranda do programa de Pós-Graduação em Produção vegetal, UFVJM. Rodovia MGT 367- Km 583, nº 5.000, Campus JK, Diamantina, MG, CEP 39100-000. Bolsista da CAPES, Email: la.madureira@yahoo.com.br
} 


\section{INTRODUÇÃO}

O sistema atual de produção de mudas para diversas espécies frutíferas utiliza recipientes com substratos adequados, que fornecem água e nutrientes para favorecer a formação das mudas em ambientes controlados, no menor tempo possível (MELETTI, L.,2011).

O fornecimento de água para satisfazer a necessidade hídrica é extremamente importante na formação das mudas, pois a falta ou o excesso de água pode limitar seu desenvolvimento. Além disso, eleva o custo de produção, pelo aumento do consumo de energia em decorrência da irrigação frequente para manter a umidade no substrato. $\mathrm{O}$ aumento do número de irrigação pode ocasionar, também, a lixiviação dos nutrientes, prolongar o tempo para o desenvolvimento das mudas e, consequentemente, aumentar o gasto com insumos, mão de obra e equipamentos, além das questões socioambientais relativas ao consumo de água que é utilizado nos viveiros.

Para melhoria desse manejo, têm-se testado diferentes composições de substratos para a produção de mudas frutíferas, visando tanto ao aspecto econômico quanto à qualidade. Assim, a utilização de polímeros hidroabsorventes favorece a retenção de água no substrato, reduzindo a frequência de irrigação durante o processo de produção de mudas de maracujazeiro.

Os polímeros hidroabsorventes foram desenvolvidos e recomendados para o uso agrícola como condicionadores do solo. Sua incorporação melhora as propriedades físicas e hídricas do solo ou substrato de cultivo, aumentando a disponibilidade de água (OLIVEIRA et al., 2004; SAAD et al., 2009).

O uso de polímeros tem favorecido o cultivo de diferentes espécies em decorrência de a capacidade de armazenamento da água no solo ser duplicada com sua incorporação ao meio de cultivo (PREVEDELLO; BALENA, 2000). Resultados satisfatórios já foram constatados na formação de mudas de cafeeiro (AZEVEDO et al., 2002), de porta-enxerto de tangerineira 'Cleópatra' (CRUZ et al., 2008), na produção de mudas de Pinus (MALDONADO-BENITEZ et al., 2011), entre outras espécies florestais. Esses resultados têm demonstrado que a aplicação de polímeros pode resultar em redução significativa na frequência de irrigação necessária, principalmente para os solos de textura leve (ABEDI-KOUPAI; ASADKAZEMI, 2006).

Em relação à frequência de irrigação, ainda são poucas as informações existentes. Os relatos já apresentados foram para a produção de meloeiro (Cucumis melo L.) com intervalo entre as irrigações de um dia com a utilização do polímero (BERNARDI et al., 2005). Entretanto, alguns pesquisadores têm enfatizado a importância de testar a dose a ser utilizada no substrato para realizar a irrigação suficiente, pois dependendo da frequência de irrigação, pode haver fornecimento de água em excesso à necessidade das plantas (MOREIRA et al., 2010; MALDONADO-BENITEZ et al., 2011). O aumenta da lâmina de irrigação em $120 \%$ da evapotranspiração prejudicou as características vegetativas do coentro no cultivo com dose 1,6 $\mathrm{g} \mathrm{kg}^{-1}$ de polímero hidroabsorvente (ALBUQUERQUE FILHO et al., 2009).

Hafle et al. (2008) testaram a utilização do polímero para o enraizamento de maracujazeiro-doce sem o uso da nebulização intermitente, técnica que demanda grande quantidade de água e energia. Com a dose próxima a $4,5 \mathrm{~g} \mathrm{~L}^{-1}$ do polímero no substrato, foram obtidos $87 \%$ de enraizamento das estacas, resultado atribuído à melhoria da retenção de água no substrato.

A disponibilidade de água no substrato é fundamental para a sobrevivência e consequente formação de mudas provenientes de propagação vegetativa ou por sementes. Contudo, é necessário adotar critérios em relação ao uso dos polímeros quanto à dose do produto comercial que será utilizada e, principalmente, à definição do intervalo de irrigação, pois a interação dos polímeros com o substrato utilizado varia de acordo com as características do ambiente de cultivo e com a necessidade das mudas.

Diante do exposto, o trabalho foi realizado com o objetivo de avaliar diferentes frequências de irrigação com a incorporação do polímero hidroabsorvente na produção de mudas de maracujazeiro-amarelo em dois tipos de substrato.

\section{MATERIAL E MÉTODOS}

O experimento foi conduzido no período de outubro a dezembro de 2011, em casa de vegetação, no município de Diamantina, Minas Gerais, situado a $18^{\circ} 14^{\prime} 56^{\prime \prime} \mathrm{S}$ e $43^{\circ} 36^{\prime} 0^{\prime \prime} \mathrm{W}$. Para monitorar as variações de temperatura durante a realização do trabalho, foi instalado um termohigrômetro digital, modelo MT 240 MINIPA no interior da casa de vegetação (Figura 1).

Foi utilizado o esquema fatorial 2 × 2 × 3 , distribuído no delineamento inteiramente casualizado, com quatro repetições e cinco plantas por parcela. Os fatores estudados foram: duas doses do polímero Hidroplan-EB ${ }^{\circledR} / \mathrm{HyB}-\mathrm{M}\left(0\right.$ e $\left.3 \mathrm{~g} \mathrm{~L}^{-1}\right)$; dois substratos $\left(\right.$ solo + esterco na proporção 3:1 (v/v) e Bioplant $\left.{ }^{\mathbb{}}\right)$; e três intervalos de reposição de água (irrigação diária, irrigação em dias alternados e irrigação a 
cada dois dias)

Aos substratos avaliados foi incorporado o polímero hidroabsorvente, efetuando-se a homogeneização das misturas. O Hidroplan-EB ${ }^{\mathbb{}} / \mathrm{HyB}-\mathrm{M}$ é um produto misto de copolímero de acrilamida e acrilato de potássio usado para absorver e reter grandes quantidades de água e nutrientes, e possui as seguintes características: $\mathrm{pH}$ da água absorvida neutra; peso específico de $1,1 \mathrm{~g} \mathrm{~cm}^{-1}$; densidade aparente de 0,8 ; tempo de absorção para $60 \%$ de equilíbrio de 30 minutos.

Foram utilizados sacos de polietileno preto perfurados da metade para o fundo, com capacidade de $650 \mathrm{~mL}$. Após o enchimento dos recipientes, foi realizada a irrigação do substrato até alcançar a saturação e o completo preenchimento dos poros. Os recipientes foram pesados a cada 24 horas, sendo esse procedimento repetido durante 15 dias, para determinar a quantidade de água perdida no processo de evaporação e drenagem em ambos os substratos e, com isso, a quantidade de água a ser reposta. Após esse procedimento, definiu-se a quantidade de $50 \mathrm{~mL}$ de água a ser fornecida nos recipientes.

Depois da realização do teste, as sementes de maracujazeiro-amarelo (Passiflora edulis Sims f. flavicarpa Deg.) foram semeadas, colocando-se duas sementes por recipiente. Durante o período de emergência, as irrigações foram realizadas diariamente para assegurar a emergência uniforme das sementes. Após a emergência, foi feito o desbaste das mudas, deixando-se apenas uma muda por recipiente e iniciada a irrigação conforme os tratamentos estabelecidos, ou seja, as mudas foram irrigadas diariamente, em dias alternados e a cada dois dias.

As mudas foram adubadas baseadas na recomendação proposta por Malavolta que indica o uso de $300 \mathrm{mg}$ de $\mathrm{N} \mathrm{dm}^{3}$ e $150 \mathrm{mg}$ de $\mathrm{K} \mathrm{dm}^{3}$ de solo para ensaio em vasos, na forma de sulfato de amônio e cloreto de potássio, respectivamente. As quantidades foram calculadas em função do tamanho do recipiente utilizado, sacos com $650 \mathrm{~mL}$ e a fonte dos nutrientes utilizada. Desta forma, foram aplicados $18,72 \mathrm{~g}$ de $\mathrm{N}$ e $37,44 \mathrm{~g}$ de $\mathrm{K}$, parceladas em três aplicações, aos 15; 30 e 45 dias após a emergência. Para isso, os adubos foram diluídos em água e aplicados ao substrato no momento da irrigação. A adubação com fósforo foi realizada apenas para o substrato formulado com solo + esterco, na proporção $3: 1(\mathrm{v} / \mathrm{v})$, ao qual foram adicionados $27,84 \mathrm{~g}$ de $\mathrm{P}$, baseada na recomendação de $450 \mathrm{mg} \mathrm{dm}^{-3}$ no momento da formulação do substrato, visto que o substrato comercial $\left(\right.$ Bioplant $^{\mathbb{R}}$ ) possui em sua composição $1,3 \mathrm{~g} \mathrm{~L}^{-1} \mathrm{de}$ P; e 2,37 $\mathrm{g} \mathrm{L}^{-1}$ de matéria orgânica.

Aos 70 dias após a emergência das sementes, quando as mudas emitiram a primeira gavinha, estágio ideal para o plantio no campo, foram avaliados o número de folhas, altura da parte aérea, diâmetro, comprimento de raiz, massa seca de parte aérea e massa seca do sistema radicular e área foliar.

A determinação do número de folhas foi feita por meio de contagem. A altura da parte aérea foi obtida medindo-se a distância do colo até o ápice, com régua graduada em milímetros. $\mathrm{O}$ diâmetro do caule foi medido utilizando-se de paquímetro digital. O comprimento de raiz foi determinado medindo-se o comprimento da raiz principal com régua graduada. A avaliação da massa seca de parte aérea e a massa seca do sistema radicular foi obtida a partir da separação do sistema radicular da parte área das mudas, com corte na inserção do colo; ambas as partes foram lavadas em água corrente, acondicionadas em sacos de papel e colocadas para secar em estufa com circulação forçada de ar a $65^{\circ} \mathrm{C}$, até atingir peso constante, para a determinação da massa seca, em balança eletrônica com precisão de $0,001 \mathrm{~g}$.

A área foliar foi avaliada seguindo a metodologia de medida de superfície, que faz uso de furadores cilíndricos para retirar discos foliares de área conhecida (BENINCASA, 2003). Para isso, foram retidos cinco discos por parcela, retirados de diferentes pontos de folhas expandidas de cada planta. Em seguida, os discos foliares foram acondicionados em sacos de papel, assim como o restante das folhas utilizadas para retirar os discos e colocados em estufa com circulação forçada de ar, a $65^{\circ} \mathrm{C}$. A área dessas folhas foi estimada a partir das relações entre matéria seca dos discos (Msd), área total dos discos, a soma das áreas de todos os discos (Ad) e a matéria seca total das folhas amostradas (Msf), das folhas usadas. Realizou-se o cálculo da área da folha $(\mathrm{AF})$, conforme a equação: $[\mathrm{AF}=(\mathrm{Msf} \times \mathrm{Ad} / \mathrm{Msd})]$.

A partir da área foliar, foi calculada a área foliar específica (AFE) $[\mathrm{AFE}=$ (área foliar/massa das folhas)] que relaciona a superfície da folha com o peso da própria folha, significando a disponibilidade de área foliar em cada grama de folha. E a razão de área foliar [RAF = (área foliar /massa total da planta)], que relaciona área foliar que está sendo usada pela planta para produzir $1 \mathrm{~g}$ de massa seca mediante a fotossíntese.

Os dados obtidos foram submetidos à análise de variância e comparação de médias, pelo teste $\mathrm{F}$ e Tukey, a $5 \%$ de probabilidade de erro para comparar os resultados obtidos. 


\section{RESULTADOS E DISCUSSÃO}

Foi observada interação entre a incorporação do polímero Hidroplan-EB ${ }^{\circledR}$ e os substratos, e entre a frequência de irrigação e as doses do polímero para todas as características avaliadas nas mudas do maracujazeiro-amarelo (altura, número de folhas, massa seca da parte aérea, diâmetro do caule, comprimento e massa seca de raízes, área foliar, área foliar específica e razão de área foliar).

Quando foi comparada a interação do polímero nos dois substratos, observaram-se os melhores resultados sobre o crescimento das mudas, exceto para a massa seca da parte aérea e do sistema radicular no Bioplant, com a adição de $3 \mathrm{~g} \mathrm{~L}^{-1}$ do Hidroplan ${ }^{\circledR}$, em ambos os substratos. E comparando-se os substratos, verificou-se que o Bioplant ${ }^{\circledR}$ proporcionou maior crescimento das mudas de maracujazeiro com e sem a incorporação do polímero, exceto para altura de planta, área foliar e comprimento de raiz sem o polímero, e diâmetro do caule com o polímero (Tabela 1).

O maior crescimento das mudas cultivadas no substrato Bioplant ${ }^{\mathbb{R}}$ pode ser atribuído à maior capacidade de armazenamento da água, comparada com a do substrato formulado com solo+esterco, pois a umidade no potencial matricial em meios mais porosos, de textura leve, é maior que nos meios de textura mais compacta com a incorporação de polímeros (OLIVEIRA et al., 2004). Isso ocorre porque os diâmetros de poros que armazenam água tornam-se superiores com a incorporação de polímeros, chegando a aumentar o diâmetro em até quatro vezes. Além disso, os polímeros são considerados uma forma eficaz de reduzir a evaporação de água e de melhorar o regime hídrico dos solos (PREVEDELLO; BALENA, 2000). Nessa condição, a absorção de nutrientes pode ser favorecida, contribuindo para o melhor desenvolvimento das mudas.

A diferença entre os substratos sugerem que a adição do polímero influencia de forma variável no meio de cultivo, em decorrência de suas características em relação à textura e à capacidade de retenção de água, e que estes fatores são essenciais para a formação das mudas. Essa diferença entre substratos com a incorporação do polímero já foi relatada na produção de mudas de outras espécies (MALDONADO-BENITEZ et al., 2011). Tais resultados evidenciam a necessidade de estabelecer, para cada tipo de solo ou substrato, a dose do polímero e a frequência de irrigação que devem ser utilizadas, além das diferenças ambientais de cada local de cultivo e, dessa forma, é imprescindível que estes fatores sejam considerados antes de sua aplicação.

As mudas de maior tamanho apresentaram menor razão de área foliar, característica importante para a atividade fotossintética, pois representa a área que está sendo usada pela planta para produção de massa seca, índice que foi menor nas mudas cultivadas com a incorporação do polímero em ambos os substratos (Tabela 1).

Outro aspecto importante observado com a incorporação do polímero foi que a formação das mudas de maracujazeiro ocorreu aos 70 dias após a emergência, alcançando tamanho adequado para o plantio no campo, enquanto as mudas sem o polímero, provavelmente, levariam mais tempo para atingir esse estádio. Resultados semelhantes foram obtidos por Tittonell et al. (2002), que verificaram que a adição de polímero ao substrato proporcionou maior precocidade, uniformidade e tamanho das mudas de pimentão.

Quanto à interação do polímero e a frequência de irrigação, foi observado que a irrigação realizada em dias alternados no substrato não prejudicou o crescimento em altura e a produção de massa seca da parte aérea, e para o número de folhas não houve diferença com intervalo de até dois dias. Já no cultivo sem adição do polímero, foi constada a necessidade de irrigar com maior frequência, notando-se menor tamanho nas mudas que não foram irrigadas diariamente (Figura 2).

Em relação ao diâmetro do caule e à produção de massa seca do sistema radicular, os resultados foram semelhantes nas mudas que foram irrigadas em dias alternados, que não diferiram daquelas que receberam água diariamente com o polímero incorporado ao substrato. E para o comprimento do sistema radicular, observou-se que a extensão não foi prejudicada com a frequência de irrigação a cada dois dias (Figura 3).

A diferença desses resultados em relação às mudas cultivadas sem a incorporação do polímero pode ser atribuída à baixa disponibilidade de água no substrato, em decorrência da absorção e da evapotranspiração das mudas, em função das variações de temperatura que ocorreram no interior da casa de vegetação (Figura 1), que podem aumentar o consumo de água nas horas mais quentes do dia. Dessa forma, o volume de água disponível para as raízes não é suficiente para manter a necessidade hídrica das plantas, quando a frequência de irrigação foi menor.

Para as características relacionadas com a área foliar, os resultados obtidos comprovaram que a presença do polímero permitiu a irrigação com intervalo maior sem prejuízos para o crescimento da área foliar específica e em razão de área foliar (Figura 4), pois, verificou-se incremento na área foliar, nas mudas cultivadas com o polímero, em todos os 
intervalos de irrigação, comparadas com mudas sem adição do polímero. O mesmo foi notado em relação à área foliar específica que relaciona a superfície foliar e o peso da folha, representando a espessura desta, observando-se que a espessura das folhas foi reduzida nas mudas cultivadas sem o polímero e submetidas a intervalos maiores na irrigação. Esses resultados refletiram na razão de área foliar, que foi menor nas mudas cultivadas com o Hidroplan ${ }^{\circledR} \mathrm{em}$ todas as frequências de irrigação realizadas, ou seja, nessas mudas, a área foliar utilizada para produzir 1 $\mathrm{g}$ é menor que naquelas que foram cultivadas sem o polímero e com o aumento da frequência de irrigação.
A redução na frequência de irrigação com a utilização de polímeros foi sugerida por Cruz et al. (2008) e constatada por Bernardi et al. (2005) na produção de meloeiro e por Azevedo et al. (2002) em mudas de cafeeiro, sem que as plantas apresentem sintomas de estresse hídrico e sem interferência no crescimento e no acúmulo de massa seca.

Os resultados obtidos neste trabalho evidenciam que a utilização de polímero aos substratos para a produção de mudas de maracujazeiro-amarelo apresenta-se como alternativa para reduzir a frequência de irrigação no viveiro.

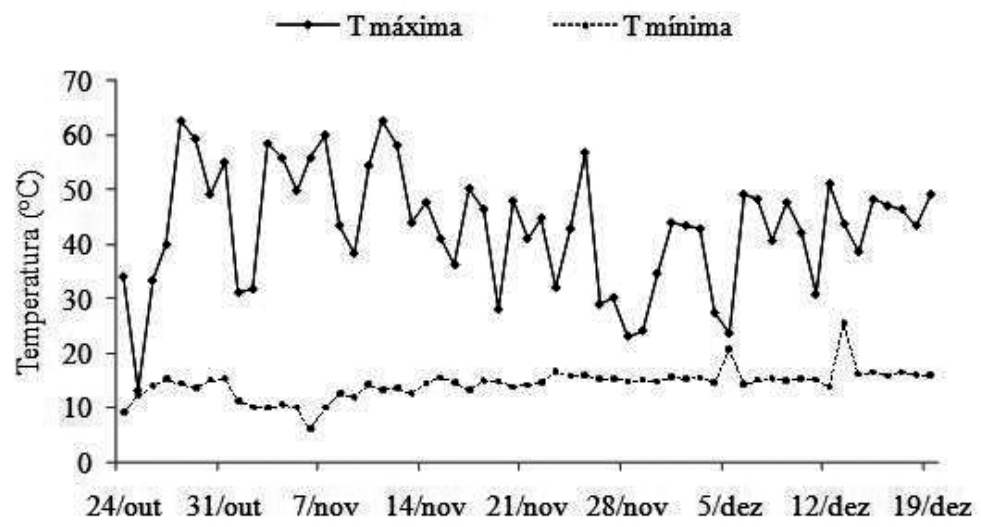

FIGURA 1-Variações das temperaturas máxima e mínima que ocorreram no interior da casa de vegetação durante o período de formação das mudas de maracujazeiro- amarelo.

TABELA 1- Interação entre o tipo de substrato utilizado e a incorporação do polímero hidroabsovente para o número de folhas, altura, massa seca da parte aérea, área foliar, diâmetro, comprimento da raiz e massa seca do sistema radicular de mudas de maracujazeiro-amarelo.

\begin{tabular}{|c|c|c|c|c|c|c|}
\hline \multirow{2}{*}{ Hidroplan $\left(\mathrm{g} \mathrm{L}^{-1}\right)$} & \multicolumn{2}{|c|}{ Altura $(\mathrm{cm})$} & \multicolumn{2}{|c|}{ Número de Folhas } & \multicolumn{2}{|c|}{ Massa seca da parte aérea $(\mathrm{mg})$} \\
\hline & Solo + Esterco & Bioplant & Solo + Esterco & Bioplant & Solo + Esterco & Bioplant \\
\hline 0 & $11,22 \mathrm{Ba}$ & $14,7 \mathrm{Ba}$ & $7,56 \mathrm{Bb}$ & $11,41 \mathrm{Ba}$ & $393,65 \mathrm{Bb}$ & $963,73 \mathrm{Aa}$ \\
\hline 3 & $21,02 \mathrm{Ab}$ & $33,23 \mathrm{Aa}$ & $8,87 \mathrm{Ab}$ & $13,06 \mathrm{Aa}$ & $952,41 \mathrm{Ab}$ & $2364,73 \mathrm{Aa}$ \\
\hline $\mathrm{CV}(\%)$ & \multicolumn{2}{|l|}{15,8} & \multicolumn{2}{|l|}{17,2} & \multicolumn{2}{|c|}{23,1} \\
\hline & \multicolumn{2}{|c|}{ Área foliar $\left(\mathrm{cm}^{2}\right)$} & \multicolumn{2}{|c|}{ Razão de área foliar $\left(\mathrm{cm} \mathrm{g}^{-1}\right)$} & \multicolumn{2}{|c|}{ Diâmetro (mm) } \\
\hline 0 & $17,36 \mathrm{Ba}$ & $18,57 \mathrm{Ba}$ & $31,8 \mathrm{Aa}$ & $14,6 \mathrm{Al}$ & $2,2 \mathrm{Bb}$ & $2,8 \mathrm{Ba}$ \\
\hline 3 & $21,35 \mathrm{Ab}$ & $27,61 \mathrm{Aa}$ & $15,6 \mathrm{Ba}$ & $10,4 \mathrm{Bl}$ & $2,7 \mathrm{Aa}$ & $3,8 \mathrm{Aa}$ \\
\hline $\mathrm{CV}(\%)$ & \multicolumn{2}{|l|}{23,1} & \multicolumn{2}{|c|}{26,1} & \multicolumn{2}{|c|}{10,8} \\
\hline & \multicolumn{3}{|c|}{ Comprimento de raiz } & \multicolumn{3}{|c|}{ Massa seca do sistema radicular (mg) } \\
\hline 0 & $18,03 \mathrm{Ba}$ & \multicolumn{2}{|c|}{$19,40 \mathrm{Ba}$} & $142,87 \mathrm{Bb}$ & \multicolumn{2}{|c|}{$462,54 \mathrm{Aa}$} \\
\hline 3 & $19,56 \mathrm{Ab}$ & \multicolumn{2}{|c|}{$21,47 \mathrm{Aa}$} & $253,92 \mathrm{Ab}$ & \multicolumn{2}{|c|}{$556,95 \mathrm{Aa}$} \\
\hline CV $(\%)$ & \multicolumn{3}{|c|}{9,4} & \multicolumn{3}{|c|}{22,7} \\
\hline
\end{tabular}

*Médias seguidas pela mesma letra, maiúscula na coluna e minúscula na linha, para cada variável, não diferem entre si, pelo teste de F, a $5 \%$ de probabilidade de erro. 

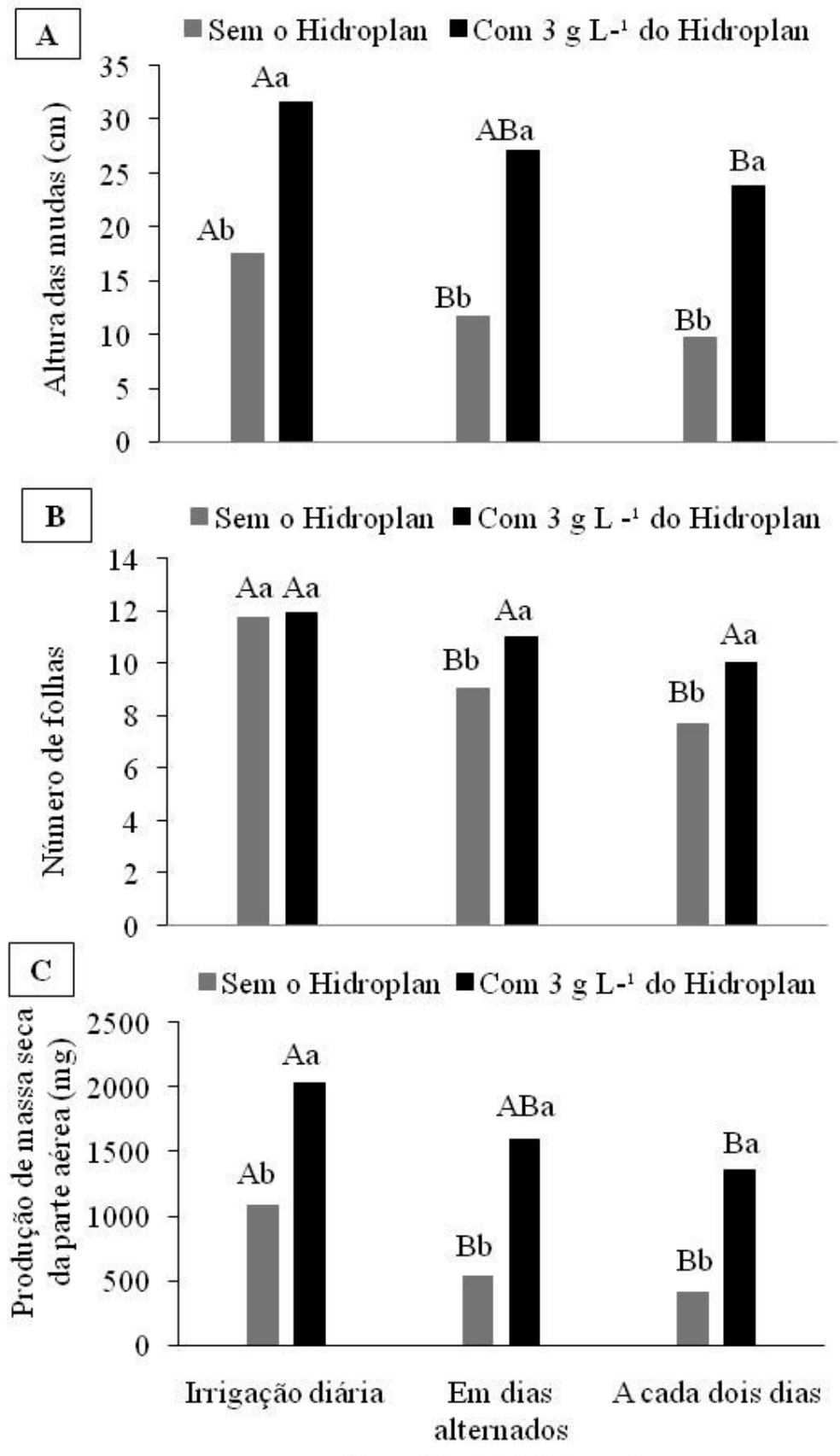

Frequência de irrigação

FIGURA 2- Altura (A), número de folhas (B) e produção de massa seca da parte aérea (C), em mudas de maracujazeiro-amarelo submetidas a diferentes intervalos de irrigação com a incorporação do polímero hidroabsorvente $\left(\right.$ Hidroplan $\left.^{\circledR}\right)$ ao substrato.

Barras de mesma cor para frequência de irrigação seguidas por letras maiúsculas iguais não diferem entre si, pelo teste de Tukey, a $5 \%$ de probabilidade de erro, e barras de cores diferentes seguidas por mesmas letras minúsculas não diferem entre si, pelo teste $\mathrm{F}$, a $5 \%$ de probabilidade de erro. 

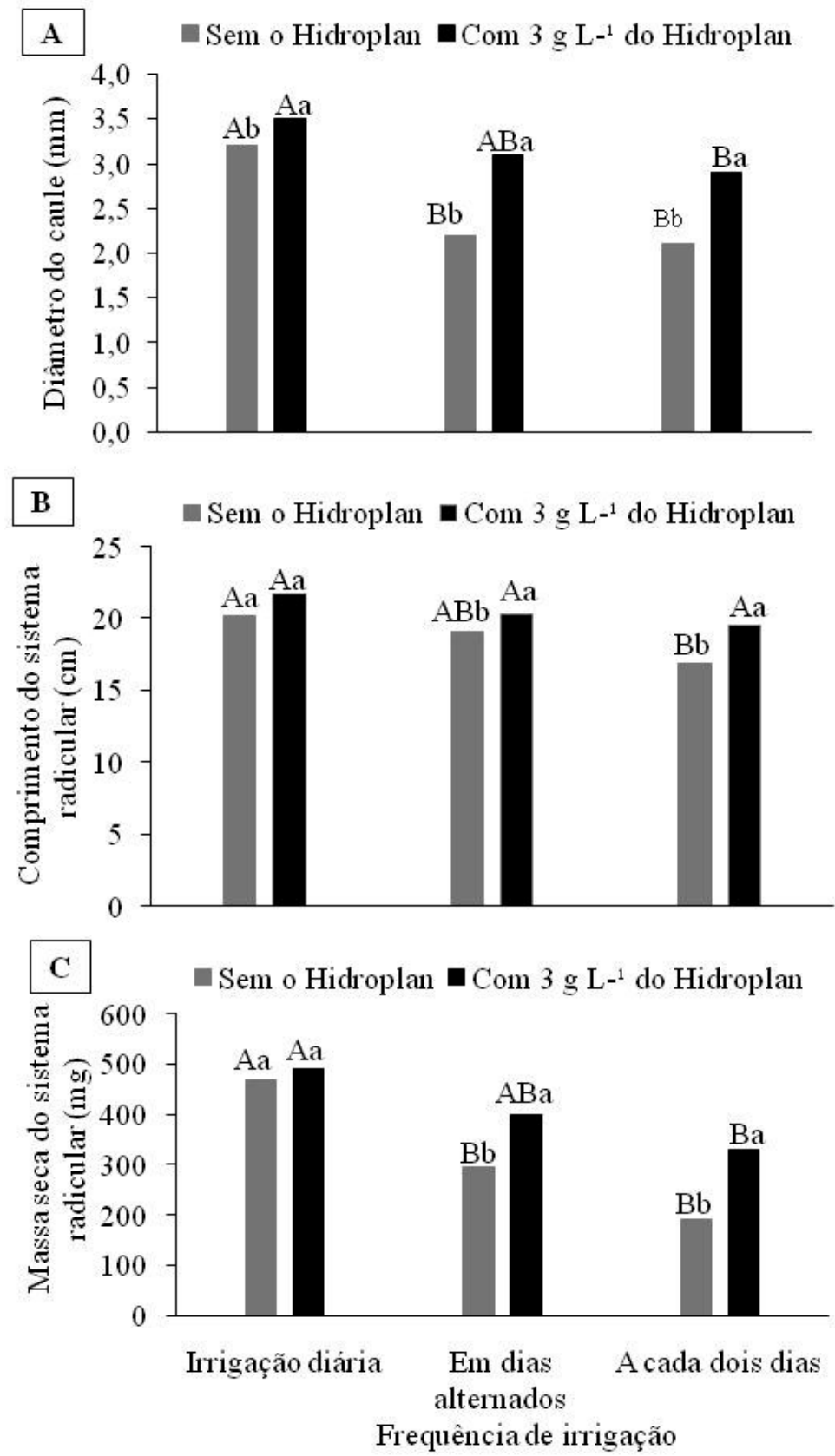

FIGURA 3 - Diâmetro do caule (A), comprimento do sistema radicular (B) e massa seca do sistema radicular (C), em mudas de maracujazeiro-amarelo submetidas a diferentes intervalos de irrigação com a incorporação do polímero hidroabsorvente $\left(\operatorname{Hidroplan}^{\circledR}\right)$ ao substrato.

Barras de mesma cor para frequência de irrigação seguidas por letras maiúsculas iguais não diferem entre si, pelo teste de Tukey, a $5 \%$ de probabilidade de erro e barras de cores diferentes seguidas por mesmas letras minúsculas não diferem entre si, pelo teste $\mathrm{F}$, a $5 \%$ de probabilidade de erro. 

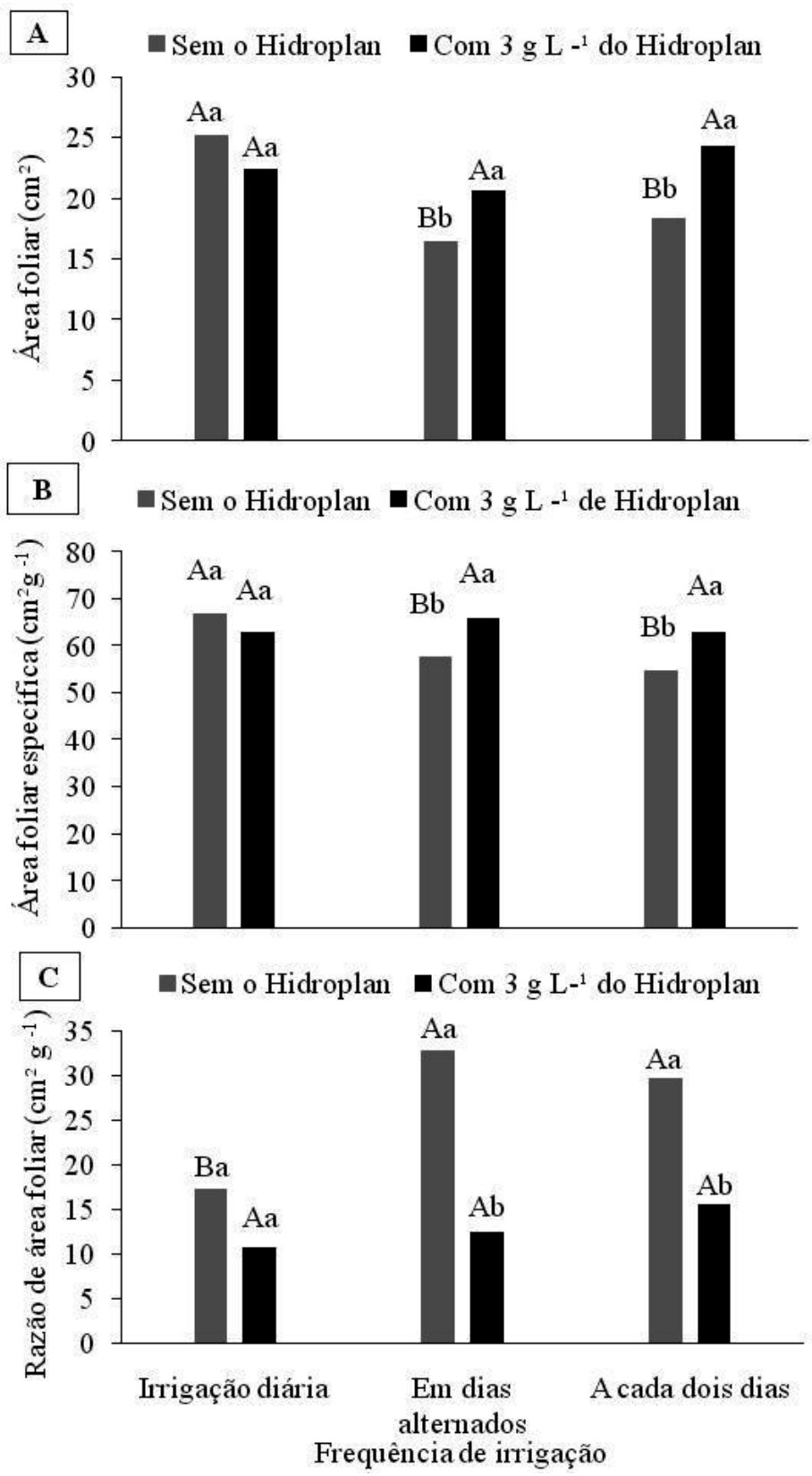

FIGURA 4- Área foliar (A), área foliar específica e razão de área foliar em mudas de maracujazeiro-amarelo submetidas a diferentes intervalos de irrigação com o polímero hidroabsorvente Hidroplan.

Barras de mesma cor para frequência de irrigação seguidas por letras maiúsculas iguais não diferem entre si, pelo teste de Tukey, a $5 \%$ de probabilidade de erro, e barras de cores diferentes seguidas por mesmas letras minúsculas não diferem entre si, pelo teste $\mathrm{F}$, a $5 \%$ de probabilidade de erro. 


\section{CONCLUSÕES}

Com a incorporação do polímero hidroabsorvente, a irrigação das mudas de maracujazeiro pode ser realizada com menor frequência, com intervalo de um dia, em ambos os substratos.

A formação das mudas de maracujazeiro-amarelo foi antecipada nos substratos que tiveram incorporação do polímero, alcançando tamanho adequado para o plantio no campo antes daquelas produzidas sem o polímero.

\section{REFERÊNCIAS}

ABEDI-KOUPAI, J.; ASADKAZEMI, J. Effects of a hydrophilic polymer on the field performance of an ornamental plant (Cupressus arizonica) under reduced irrigation regimes. Polymer Journal, Singapore, v.15, n. 9, 2006.

ALBUQUERQUE FILHO, J. A. C.; LIMA, V. L. A.; MENEZES, D.; AZEVEDO, C. A. V.; DANTAS NETO, J.; SILVA JÚNIOR, J. G. Características vegetativas do coentro submetido a doses do polímero hidroabsorvente e lâminas de irrigação. Revista Brasileira de Engenharia Agrícola e Ambiental, Campina Grande, v.13, n.6, p. 671-679, 2009.

AZEVEDO, T. L. F.; BERTONHA, A.; GONÇALVES, A. C. A.; FREITAS, P. S. L.; REZENDE, R.; FRIZZONE, J. A. Níveis de polímero superabsorvente, frequências de irrigação e crescimento de mudas de café. Acta Scientiarum, Maringá, v. 24, n.5, p.1239-1243, 2002.

BENINCASA, M. M. P. Análise de crescimento de plantas: noções básicas. Jaboticabal: FUNEP, 2003. 42 p.

BERNARDI, A. C. C.; TAVARES, S. R. L.; SCHMITZ, A. A. Produção de Meloeiro utilizando um polímero hidrofílico em diferentes frequências de irrigação em casa de vegetação. Revista Irriga, Botucatu, v. 10, n. 1, p. 82-87, 2005.

CRUZ, M. C. M.; HAFLE, O. M.; RAMOS, J. D.; RAMOS, P. de F. Desenvolvimento do Porta-Enxerto de Tangerineira 'Cleópatra'. Revista Brasileira de Fruticultura, Jaboticabal, v. 30, n. 2, p. 471-475, 2008.
HAFLE, O. M.; CRUZ, M. C. M.; RAMOS, J. D.; RAMOS, P. S.; SANTOS, V. A. Produção de mudas de maracujazeiro-doce através da estaquia utilizando polímero hidrorretentor. Revista Brasileira de Ciências Agrárias, Recife, v.3, n.3, p.232-236, 2008.

MALDONADO-BENITEZ, K. R.; ALDRETE, A.; LÓPEZ-UPTON, J.; VAQUERA-HUERTA, H.; CETINA-ALCALÁ, V. M. Producción de Pinus greggii Engelm. en mezclas de sustrato con hidrogel y riego, en vivero. Agrociencia, Montecillo, v.45, p. 389-398. 2011.

MELETTI, L.M.M., Avanços na fruticultura tropical no Brasil. Revista Brasileira de Fruticultura, Jaboticabal, v. 33, n.1 - edição especial, p. 73 - 75. 2011.

MOREIRA, R. A.; RAMOS, J. D.; CRUZ, M. C. M.; VILLAR, L.; HAFLE, O. M. Efeito de doses de polímero hidroabsorvente no enraizamento de estacas de amoreira. Revista Agrarian, Dourados, v.3, n.8, p.133-139, 2010.

OLIVEIRA, R. A. DE; REZENDE, L. S.; MARTINEZ, M. A.; MIRANDA, G. V. Influência de um polímero hidroabsorvente sobre a retenção de água no solo. Revista Brasileira de Engenharia Agrícola e Ambiental, Campina Grande, v.8, n.1, p.160-163, 2004.

PREVEDELLO, C. L.; BALENA, S. P. Efeitos de polímeros hidrorretentores nas propriedades físico-hídricas de dois meios porosos. Revista Brasileira de Ciência do Solo, Viçosa, MG, v. 24, p. 251-258, 2000 .

SAAD, J. C. C.; LOPES, J. L. W.; SANTOS, T.A. Manejo hídrico em viveiro e uso de hidrogel na sobrevivência pós-plantio de Eucalyptus urograndis em dois solos diferentes. Engenharia Agrícola, Jaboticabal, v.29, n.3, p.404-411, 2009.

TITTONELL, P. A.; GRAZIA, J. DE; CHIESA, A. Adición de polímeros superabsorbentes en el medio de crecimiento para la producción de plantines de pimiento. Horticultura Brasileira, Brasília, v. 20, n. 4, p. 541-645, 2002. 